\title{
O CANON DO CONSUMO DO UNIVERSO STAR TREK NO BRASIL
}

\author{
Franciani Fernandes Galvão \\ Olga Maria Coutinho Pépece \\ Luciano Mota
}

Franciani Fernandes Galvão Doutoranda do Programa de Pós-Graduação em Administração da Universidade Estadual de Maringá - UEM. E-mail: comexfran@hotmail.com.

Olga Maria Coutinho Pépece é Professora do Programa de Pós-Graduação em Administração da Universidade Estadual de Maringá - UEM. E-mail:

opepece@gmail.com.

Luciano Mota é Graduando em

Administração pela Universidade

Estadual de Maringá - UEM. E-mail:

lucianomota_@hotmail.com..

Os autores agracedecem aos avaliadores pelos comentários para melhoria do artigo.

\begin{abstract}
Resumo
Esta pesquisa tem como objetivo descrever como se dá o consumo do Universo Star Trek (UST) pelos fãs no Brasil. Seguindo os pressupostos referentes à Teoria da Cultura de Consumo, a pesquisa com natureza qualitativa e fins descritivos, buscou identificar e descrever, a partir da análise de conteúdo, o referido consumo pela imersão no ambiente de fã do Star Trek no Brasil. Os dados foram coletados: por observação e entrevista com grupos de fãs de comunidades sociais como o Second Life, facebook e whatsapp; pela participação como membro de fãs clubes em grupos de discussão on line; pela participação em eventos presenciais; pela análise de séries, filmes e documentários disponíveis em arquivo eletrônico; bem como, pela identificação de produtos para consumo em buscas na internet. Os resultados permitiram a criação de um Canon da Cultura de Consumo Star Trek e este explica o consumo do UST no país.

Palavras-chave: Star Trek, Fãs, Cultura de consumo, Metáforas do consumo, Expressão material.
\end{abstract}

Esta obra está licenciada com uma Licença Creative Commons Atribuição 4.0 Internacional.

\section{INTRODUÇÃO}

As pesquisas sob a temática de fãs tem se ampliado com o passar dos anos, entendendo que esta deteria um caráter cultural importante nas sociedades que estudam comportamentos sociais. 0 fã hoje tem possibilidade de compartilhar preferências amplamente, dispondo de maior acesso a bens e informações para saciar seu desejo de ligação com heróis ou vilões da ficção científica ou de outras fantasias. Isso também refletiu na academia, as pesquisas têm mostrado que programas de TV podem contribuir para uma identidade social do indivíduo e aumentar a comunidade de grupos (Kozinets, 2001; Vieira \& Appio, 2010), advindo 
daí a oportunidade de estudos de fãs ou fandoms.

Dentre os segmentos populares que retratam a cultura de adoração a artistas, desenhos, filmes, etc, hoje, são vistos consumidores adoradores de vinho, leitores inveterados, fotógrafos amadores, otakus, cosplayers, trekkies, entre outros, e todos possuem interesses em algo que os aglutina em comunidades de interesses em comum, o que geralmente os direciona para alguma forma de consumo. E para entender a diferença entre os subgrupos de fãs, deve-se estudar mais a fundo esses consumidores (Grossberg, 1992), delineando assim as fronteiras entre os fãs que pertencem à subcultura de ficção científica Star Trek, os trekkies e o resto da população que é fã (Kozinets, 2001) com intenção de distinguí-los.

Esta pesquisa estuda a subcultura trekkie, fãs do "Sistema Star Trek" ou "Universo Star Trek" (UST) (Kozinets, 2001), no Brasil. 0 fandom Star Trek é diferente de outros fenômenos fandom de cultura popular, por superá-los em termos de profundidade e amplitude de criações oficiais e não oficiais (Frazetti, 2016).

Esta pesquisa tem como objetivo geral descrever como se dá o consumo do Universo Star Trek (UST) pelos fãs no Brasil. Como objetivos específicos, busca identificar os ativadores do consumo, o consumo como participação, a expressão material do consumo e a identificação do trekkie junto a seus pares.

No Brasil, segundo Vieira (2017), os estudos sobre a cultura de fã são crescentes, contando com grupos de pesquisa, sobretudo na área da Comunicação, com pesquisadores na USP (telenovelas), UFSCAR (narrativas de seriados), UNISINOS (cultura nerd), UFF (big brother Brasil), UFRJ (celebridades) e UFPE (música pop).

Este estudo segue os pressupostos referentes à Teoria da Cultura de Consumo, de natureza qualitativa com fins descritivos, buscando identificar e descrever, a partir da análise de conteúdo, o consumo do trekkie no Brasil. Os dados foram coletados por uma imersão no ambiente de fã de Star Trek no Brasil. Para tanto um dos autores participou como membro de grupo em comunidades sociais digitais (Facebook e Second Life), em fãs clubes, e em eventos presenciais sobre o tema; os autores também coletaram dados de séries, filmes e documentários disponíveis em arquivo eletrônico; e realizaram busca de produtos para consumo disponíveis na internet.

Para a realização deste artigo, o referencial teórico propiciará a compreensão da subcultura de fã, do consumo, e da criação do Universo Star Trek. Na sequência será apresentado o método utilizado, a classificação dos grupos, a análise dos dados e as considerações finais.

\section{REFERENCIAL TEÓRICO \\ Subcultura de fã e fandom}

Fandom, é um fenômeno sociocultural amplamente associado com sociedades capitalistas modernas, mídias eletrônicas, cultura de massa e performance pública (Duffett, 2013). Na maioria das pesquisas existe uma tendência de falar sobre o fenômeno como se este sempre tivesse existido, contudo sua primeira aparição foi no século XVII na Inglaterra, como uma abreviação para a palavra fanático (cunho religioso). Duffett (2013) afirma que o fandom se originou como uma resposta às condições históricas específicas e essas condições decorreram de mudanças na mídia e sua tendência para reconfigurar à experiência cotidiana.

Nesta sociedade pós-moderna existe uma profusão de diferenciados estilos e tipos culturais entre as comunidades, como entusiastas de pets, provadores de vinhos, connaisseurs de café, filatelistas, bibliófilos, entusiastas de body-building, nerds, etc., sendo algumas das várias subculturas que constroem comunidades baseadas na predileção sofisticada e expansiva para o consumo de objeto ou texto (Kozinets, 1997). Os membros destas comunidades ou grupos são entusiastas do consumo, e tem sua auto-identificação como o membro de um grupo social de entusiastas individuais (Kozinets, 1997; Schouten \& Mcalexander, 1995) que compartilham a competência cultural em algum grau (Sirsi, Ward \& Reingen, 1996), engajando-se em atividades produtivas relacionadas aos seus gostos (Kozinets, 1997).

Diante destes movimentos culturais existe a cultura de fã, entendida como membros pertencentes a um determinado grupo de gostos e predileções por produtos e textos, neste caso, da ficção. Esses fãs engajam-se em atividade produtiva que resulta na criação de novos 'textos' relacionados ao consumo de 
objetos (Kozinets, 1997, Fiske, 1987, 1989, Grossberg, 1992, Lewis, 1992). Para este contexto, alguns pesquisadores apontam distinções entre fãs e aqueles considerados apenas seguidores.

Segundo Tulloch e Jenkins (1995, p. 23) fãs são "participantes ativos de um fandom como uma instituição intepretativa social e cultural", seguidores são os "membros da audiência que assistem regularmente e apreciam os programas de ficção científica na mídia, mas que afirmam não ter maior identidade social com base neste consumo". Neste sentido, esta pesquisa, buscou o contato com fãs e não apenas seguidores, são fãs aqueles que fazem parte de fã clube ou organização que visa propagar informações sobre o elemento de admiração.

A interação ativa dos membros proporciona a ampliação das atividades para incluir não somente a experiência e as atividades de integração aproveitada pelos fãs devotados e casuais, mas o consumo como participação (Holt, 1995) e atividades de classificação, como por exemplo, o consumo de jogos virtuais como o ambiente Trivia ou o consumo do RPG que promove comunhão e socialização entre seus consumidores (Kozinets, 1997). O consumo como integração e classificação também inclui o uso de uniformes e adereços do Star Trek quem permitem classificar, pela posse de significados culturais compartilhados pertencentes ao objeto, seus consumidores (Kozinets, 1997, Holt, 1995, Mccracken, 1986).

\section{Consumo}

Se a cultura é a definição do que uma sociedade é, o consumo é uma de suas representações mais distintas, pois, os consumidores escolhem as marcas para comunicar sua identidade ambicionada (Hollenbeck \& Patrick, 2016, Belk, 1988, Holt, 1995). Assim, o consumo permite aos consumidores integrarem-se a si mesmos e aos objetos, permitindo-se, assim, o acesso a propriedades simbólicas do objeto (Holt, 1995) e estas propriedades servem para classificar consumidores, para construir afiliações e ou aumentar distinções (Goldsmith \& Clark, 2012).

Quanto ao consumo, sendo ele o que por consequência consumimos, é a extensão de nossas identidades, o consumo é um componente de importância para propiciar a compreensão da identidade dos indivíduos, o significado atribuído ao que consomem, o que desejam comunicar e como constroem o seu eu (Belk, 1988). Pode, inclusive, ser visualizado em termos estruturais, pois consiste em ações nas quais consumidores se engajam diretamente com objetos de consumo (ações de objetos) e interações com outras pessoas às quais fazem uso dos objetos de consumo como recursos focais (ações interpessoais), porém, em termos de finalidade, as ações dos consumidores podem ser tanto um fim em si mesmas (ações autotélicas) quanto meios para alguns finais (ações instrumentais) (Holt, 1995).

Lee e Luster (2015) comentam que os consumidores sempre usaram objetos para expressar seu auto-conceito e identidade para outros, inclusive, no tocante à ampliação de sua base social de conecções para expressar sua identidade e auto-conceito (Holt, 1995) e para ajudar a articular quem eles são para os outros (Mccracken, 1986). Também a posse de objetos é conhecida por ser o ponto de integração no desenvolvimento e manutenção de relações interpessoais (Lee \& Luster, 2015, Holt, 1995, Solomon, 1983). Estes objetos são aqui associados ao consumo de textos e produtos do Universo Star Trek, pois os consumidores são produtores ativos de significados e o fazem principalmente em relação aos produtos que consomem para os seus próprios fins (Arnould \& Thompson, 2005, Campbell, 2005, Featherstone, 1991; Holt, 1995, Kozinets, 2002; 2001).

Levando ao que Holt (1995) designa como competência cultural, este seria um termo específico significando compreensão culturalmente situada de termos gerais de práticas de consumo, ou seja, são formas particulares pelas quais as pessoas compreendem, avaliam, usam e apreciam o consumo de objetos sob diferentes contextos. Assim, o consumo de objetos é essencial na participação desses grupos porque eles providenciam a matéria prima que permite, por meio de sua comunicação simbólica, a união das pessoas na interação lúdica (Kozinets, 1997, Holt, 1995).

Os produtos, sob uma perspectiva econômica, são concebidos como grupos de atributos que proporcionam benefícios 
particulares, porém, pela perspectiva simbólica, "são concebidos como vasos de significados que significam de forma semelhante para todos os consumidores" (Holt, 1995, p. 1). Logo, entendendo que os produtos são consumidos de formas variadas por diferentes grupos, esta variação nas ações de consumo sugerem oportunidades de pesquisa, com vistas a descrever estas variedades de maneiras pelas quais as pessoas consomem, entender as diferenças entre grupos e explicar as condições de consumo de diferentes grupos (Holt, 1995), esta pesquisa busca demonstrar esta variedade de maneiras como o UST é consumido no Brasil.

\section{Star Trek}

Star Trek é uma série de ficção científica espacial que versa sobre as disputas sociais e políticas de povos do planeta terra e de vários outros planetas 300 anos à frente desta época, num futuro onde a humanidade é sobrevivente e triunfa sob as adversidades da sociedade atual (Paramount Brasil, 2016). Conforme o site Trek Brasilis (2016) descreve:

As aventuras da galante tripulação de uma nave espacial terrestre nos confins do espaço, em algum ponto do futuro (que acabou, posteriormente, sendo definido como meados do século 23). Os humanos estariam em situação muito melhor que a atual, e a Terra seria um paraíso, sem conflitos, guerras ou problemas sociais. Restaria aos terráqueos apenas a busca pelo desconhecido, novos mundos e civilizações, como forma de aprimorar ainda mais sua sociedade e seu conhecimento.

Idealizada pelo escritor George Clayton Johnson (projeto piloto), foi roteirizada e posteriormente escrita por Gene Roddenberry para a televisão nos Estados Unidos, a série original teve início em 1966 e durou até 1969. Depois desta, originaram-se outras seis séries: Star Trek Animated (1973-1974); Star Trek: The next generation - TNG (1987-1994); Star Trek: Deep space nine - DS9 (1993-1999); Star Trek: Voyager - VOY (1995-2001); Star Trek: Enterprise - ENT (2001-2005) e Star Trek: Discovery - DSC (2017-2018), e 13 filmes desde 1979.

Para os fãs leais, a série Star Trek é vista como um dos grandes fenômenos de consumo do nosso tempo (Kozinets, 2001), pois foi já considerada o fenômeno Cult mais bem sucedido e lucrativo na história da televisão (Entertainment Weekly, 1994), e um dos principais ícones da cultura pop do século 20. "A franquia Star Trek tem sido uma figura central na cultura americana por quarenta e cinco anos, e é uma das poucas criações que pode gabar-se de uma abrangência global. Star Trek cruzou fronteiras culturais e deu origem a uma cultura de fãs altamente complexa." (Frazetti, 2016, p. 279). Portanto, ao completar mais de cinquenta anos de existência e com reconhecimento como ícone da cultura popular, é importante visualizar como ainda hoje é objeto de desejo de consumo para fãs de várias idades e países.

\section{MÉTODO DA PESQUISA}

Este estudo segue os pressupostos referentes ao espírito da Teoria da Cultura de Consumo (Levy, 2015) que busca pesquisar as situações de consumo, levando em conta os papéis de diferentes perspectivas e dimensões experienciais e socioculturais do consumo. É uma pesquisa com postura epistemológica de natureza qualitativa com fins descritivos, buscando identificar os significados interpretativos do consumo.

0 ponto de partida foi a identificação de estudos no contexto de cultura de consumo e da temática Star Trek. Em seguida foi feita a imersão em campo em conjunto com o estudo aprofundado sobre a cultura de fãs e sobre o Universo Star Trek - UST. Cabe aqui salientar que, o ano de 2016 foi a data de comemoração dos 50 anos de criação da série Star Trek, o que deixou mais aparente a qualificação de fãs e possibilitou um maior número de textos e produtos relacionados ao tema, propiciando melhor interação e imensão.

A coleta foi efetuada a partir do acesso ao núcleo de fãs, para isso, um dos pesquisadores teve acesso como fã membro junto a grupos virtuais do Brasil. 0 primeiro acesso foi efetuar o levantamento e a adesão ao maior número de grupos brasileiros no facebook, entre julho de 2016 e julho de 2017. Em seguida foi efetuado o acesso como membro em treinamento ao grupo USS Venture no Second Life, incluindo a participação em grupo no facebook e em grupo no whatssapp. Neste meio tempo os pesquisadores passaram a fazer a análise global 
dos episódios da série (TNG, DS9, ENT e VOY), filmes e documentários (melhor pontuados no site $\mathrm{IMDb}^{1}$ ). A participação como membro no Fã Clube "Federação dos Planetas Unidos" (Curitiba) ocorreu após a participação na $20^{\mathrm{a}}$ Trekcon (2016) e durou até a 21 a Trekcon (2017), perfazendo aproximadamente um ano de permanência no grupo e seis meses como membro do fã clube. A participação no grupo do whatssap do fã clube nacional Star Trekkers foi de quatro meses. Por fim, foram identificados sites de acesso nacional com venda de produtos de identidade Star Trek.

A análise de conteúdo foi utilizada para trabalhar os dados, este é o método mais comumente adotado no tratamento de dados de pesquisas qualitativas (Minayo, 2000), por envolver iniciativas de explicitação, procedimentos de sistematização e objetivar a expressão do conteúdo de mensagens para efetuar deduções lógicas e justificadas sobre a origem das mensagens (quem as emitiu, em que contexto e/ou quais efeitos se pretende causar por meio delas) recorrendo à criação de indicadores e levando à criação de categorizações (Bardin, 1979; 2006). Especificamente, a análise de conteúdo é um:

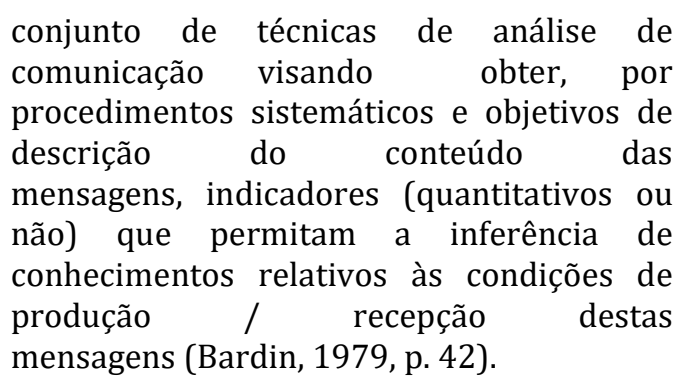

As categorias de análise foram criadas para conter os indicadores da comunicação identificados com os dados de pesquisa sobre o consumo, estes foram trabalhados para definir o consumo do UST classificando-os em grupos principais, sendo eles: ativadores de consumo, consumo como participação, expressão material do consumo e identificação dos fãs junto aos pares. Cabe esclarecer que as categorias levantadas foram aportadas com conteúdo teórico pela abordagem abdutiva ou combinação sistemática (Dubois \& Gadde, 2002). Como fim, a intenção foi definir um Canon do consumo do Universo Star Trek pelos fãs no Brasil, se enquadrando com a ideia de
Kozinets (1997) da Cultura de Consumo Star Trek (Star Trek Culture of Consumption - STCC).

\section{OS GRUPOS}

\section{Ativadores do consumo}

Os itens principais que levam ao consumo do UST são as séries e filmes, esses são os principais ativadores de consumo, pois, é a partir do consumo destes que é desencadeado o consumo derivado.

a) Séries: As séries foram investigadas para identificar a existência de sugestões de itens para consumo, e as formas de consumo que suscitassem à compra. Porém, ao assistir os episódios das séries TNG, DS9, ENT e VOY não foram verificadas a incitação direta ao consumo no formato de propaganda ou merchandising de produtos. Porém, a ideologia, idumentária, artefatos, armas e alimentos são objetos que despertam o desejo do fã para o consumo. A partir da veiculação e absorção pelo fã, ele deseja possuir tais objetos e assim, há a ativação do consumo por parte do fã, como o consumo de trajes dos tripulantes e demais espécies de seres. 0 que pode ser verificado enquanto ideia de consumo são: a visão do não desperdício, a aceitação ou rejeição dos alimentos e produtos sintetizados, a troca cultural e de objetos com outras espécies, ideias de economia de recursos, conhecimento intelectual como ideal. Outras formas pontuais observadas nos episódios dentro do limite das bases e naves, relacionadas ao consumo por parte dos tripulantes são: entretenimento e treinamento no Holodeck ou Holosuite (salas com imagens geradas em forma de holograma), bares e restaurantes (VOY, TNG, DS9), lojas (DS9). As ideologias apresentadas como religião (DS9) e a assimilação pelos Borgs (estes personagens procuram consumir assimilar - o corpo e a tecnologia de outras espécies que possam agregar à coletividade Borgs).

b) Documentários: Foram levantados os documentários relacionados à Star Trek a fim de se identificar se haveria incentivo ao consumo de produtos do UST. Para isso, foram identificados os documentários mais bem pontuados do site IMDb, com notas iguais ou superiores a sete pontos. A seleção inicial contou com 60 documentários mencionados pelo site, porém, com a classificação acima de 
sete pontos, somente 16 (Tabela 1) documentários foram selecionados. A maior parte dos documentários tratava de temas como curiosidades das gravações, discussões sobre episódios, a influência dos filmes/séries de Star Trek na área de tecnologia. Dentre os documentários, de modo geral, não há incitação ao consumo direto de artefatos relacionados à Star Trek, porém os bonés, camisetas e jaquetas utilizados pela equipe dos filmes durante as entrevistas, podem se tornar objetos almejados pelos fãs após assistí-los. Além disso, entendese que assistir ao documentário, por si só, já é um ato de consumo do UST. A intenção dos pesquisadores para seleção dos documentários foi associar possíveis direcionadores de consumo e relacioná-los à pontuação qualitativa da nota do IMDb, contudo, por não expressão esta direção, entende-se que os documentários são enquadrados como objetos de consumo e não incitação plena ao consumo ST.

\section{Tabela 1}

Documentários relacionados ao Universo Star Trek

\begin{tabular}{|c|c|c|c|}
\hline Documentário & Ano & Temp & $\begin{array}{l}\text { Nota } \\
\text { IMDb }\end{array}$ \\
\hline Our Star Trek: The Fifty Year Mission & 2015 & $10 \min$ & 9,5 \\
\hline Star Trek Tech & 2007 & $60 \min$ & 8,4 \\
\hline The Real Story: Star Trek & 2013 & $49 \mathrm{~min}$ & 8,3 \\
\hline The Twenty-Five Year Mission Tour & 1992 & $6 \min$ & 8,2 \\
\hline The Weakest Link: Star Trek EditionThe Weakest Link: Star Trek Edition & 2001 & $44 \min$ & 8,2 \\
\hline Mind Meld: Secrets Behind the Voyage of a Lifetime & 2001 & $75 \min$ & 8,1 \\
\hline Star Trek: The Captains' Summit & 2009 & $70 \mathrm{~min}$ & 8,1 \\
\hline After They Were Famous: Star Trek & 1999 & $42 \min$ & 7,8 \\
\hline Star Trek Evolutions & 2009 & $75 \mathrm{~min}$ & 7,8 \\
\hline Star Trek: The Next Generation - Regeneration: Engaging the Borg & 2013 & $30 \mathrm{~min}$ & 7,6 \\
\hline How William Shatner Changed the World & 2005 & $90 \mathrm{~min}$ & 7,5 \\
\hline The Science of Star Trek & 1995 & $48 \mathrm{~min}$ & 7,5 \\
\hline Earthlings: Ugly Bags of Mostly Water & 2004 & $70 \mathrm{~min}$ & 7,4 \\
\hline Star Trek: 30 Years and Beyond & 1996 & $90 \mathrm{~min}$ & 7,4 \\
\hline Trek Nation & 2011 & $88 \mathrm{~min}$ & 7,4 \\
\hline Leonard Nimoy: Star Trek Memories & 1983 & $49 \mathrm{~min}$ & 7,3 \\
\hline Bring Back... Star Trek & 2009 & $75 \min$ & 7,1 \\
\hline Pioneers of Television: Science Fiction & 2011 & $55 \mathrm{~min}$ & 7,1 \\
\hline Trekkies & 1997 & $86 \mathrm{~min}$ & 7 \\
\hline William Shatner Presents: Chaos on the Bridge & 2014 & $59 \min$ & 7 \\
\hline
\end{tabular}

Fonte: Dados de pesquisa.

\section{Consumo como participação}

Uma das características do consumo do UST é o consumo como participação. Esta forma de consumo foi classificada dentro das metáforas de consumo por Holt. Para Holt (1995), existem quatro correntes de pesquisa retratando como os consumidores compram: consumo como experiência, consumo como integração, consumo por classificação e consumo como participação.

Apesar das quatro formas de consumo, a principal observada a partir desta pesquisa foi o consumo como participação ou "Play" ou mesmo jogo. A quarta metáfora propõe que o 
uso de objetos de consumo ocorram como recursos para interagir com colegas consumidores e não somente pela interação com o objeto. Esta dimensão pode ser dividida em autotélica e componentes instrumentais. Práticas como participar dos grupos nas redes sociais, no whattsapp, ir aos eventos do UST, capturam a 'dimensão autotélica' (Simmel, 1950): interação consumidor-objetoconsumidor que não tem final ulterior, interação para interação de causa (Holt, 1995). Essas práticas acabam definindo os papéis e regras assumidas por aqueles que participam (play, brincam, jogam), tornando o objeto de consumo, que neste caso pode ser virtual, ou mesmo uma participação em um evento, essencial para participar do grupo de fãs, pois este consumo provém os materiais ou os componentes instrumentais necessários, segundo imposição dos fãs, para que cada consumidor que assim o desejar passe a ser considerado integrante e possa interagir com o grupo efetivo de fãs (Holt, 1995).

\section{a) Second Life (SL): USS Venture}

0 grupo USS Venture foi criado como site em 2002 (www.ussventure.eng.br) contendo informações sobre o UST. Os membros da tripulação na época iniciaram também a simulação deste universo em PBEM (Play by email) ${ }^{2}$, simulando a vida a bordo de uma nave estelar da federação. Foi somente em 2008 que os membros começaram as atividades no Second Life, criando a unidade de simulações operacionais e táticas para a nave estelar que construíram na ilha chamada Trivas.

Semelhante à formação militarizada do metauniverso Star Trek, esta ilha é comporta por avatares que têm a possibilidade de experiênciar missões, utilizando idumentária e patentes iguais às da série, simulando situações e contextos da academia da Frota Estelar. Para fazer parte do grupo o aspirante deve fazer inscrição e passar por prova objetiva assumir a posição inicial que é a de cadete e sucessivamente fazer provas objetivas e práticas para ascender de cargos para alferes, tenente junior e tenente, tenente comandante $\mathrm{e}$ comandante, capitão, comodoro, vice-almirante e almirante. Além disso, os participantes devem se enquadrar nas divisões de atuação que comportam: comando, comunicação, ciências, engenharia, operações, nível tático, cadetes e civis (USSVenture, 2018). A Figura 1 (na ponte de uma das naves) demonstra os membros em atividade denominada 'missão' (ocorrem todos os domingos). As missões são simulações criadas por tripulantes, e podem simular coleta de material para abastecer a estação, salvamento de tripulantes, para exploração de novos planetas, etc.. A base estelar requer manutenção, pois foi configurada propositalmente pelos programadores para fazer com que os membros sintam-se em uma estação funcional do ST, com cronograma de atividades semanais de treinamentos, missões, aulas, avaliações, saídas de campo, eventos culturais, etc. Uma das atividades que ocorrem durante o ano, é a formatura de oficiais (Figura 2), que conta com ambiente especialmente criado (renderizado) para a cerimônia e conta com a presença de membros tripulantes e convidados de outras ilhas do Second Life.

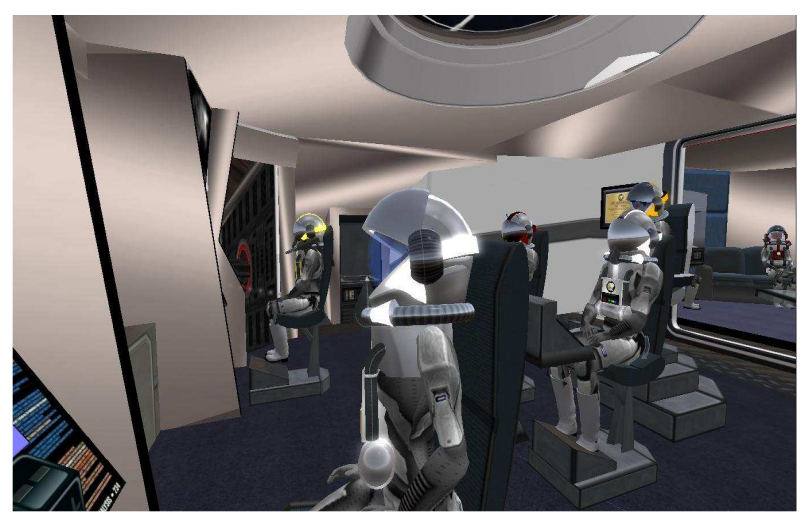

Fonte: Dados de pesquisa.

Figura 1. Second Life: missão do grupo USS Venture

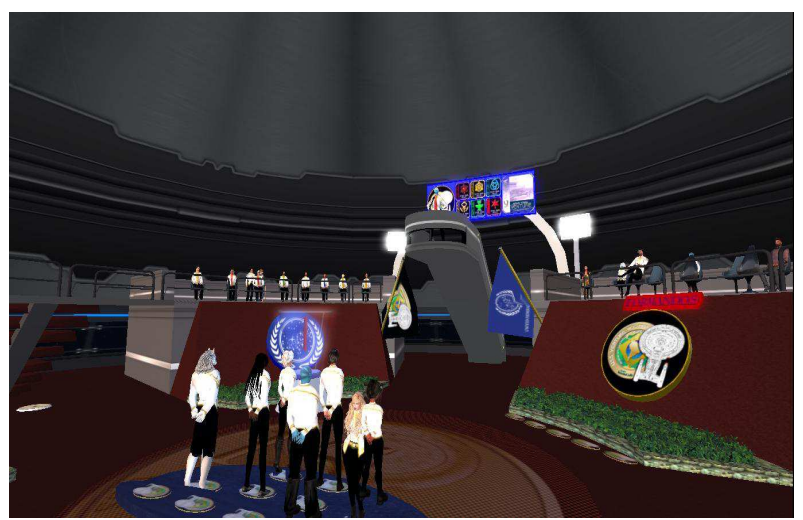

Fonte: Dados de pesquisa.

Figura 2. Second Life: cerimônia de formatura de oficiais da USS Venture

Neste microgrupo cultural dentro do subgrupo cultural trekkie, o consumo de Star 
Trek se dá pela imersão no UST, consumindo o jogo como forma de experienciar as missões, a vivência, os treinamentos e a convivência com outros fãs, legitimando e expressando o que importa para o indivíduo e para o grupo. As práticas de consumo são influenciadas pelo contato entre os pares dentro e fora do SL, pelas 'afinidades socialmente estruturadas' (Kozinets,
2001) e pelo significado individual de ligação com a ficção. A presença ocorre de maneira online, com a criação de avatar para acesso ao ambiente, mas alguns dos membros participam fisicamente e de forma online em eventos relacionados ao Star Trek representando o grupo. As atividades de consumo identificadas estão apresentadas no Quadro 1:

\begin{tabular}{|c|c|}
\hline Atividades & Produtos \\
\hline \multirow{3}{*}{ Criação de conteúdo } & $\begin{array}{l}\text { Canal no You Tube: o grupo detém um canal com vídeos de unboxing de } \\
\text { coleções compradas, vídeos de missões do grupo, documentários, filmes de } \\
\text { fãs, matérias jornalísticas e entrevistas feitas dentro do SL com membros } \\
\text { do grupo informando melhorias na ilha e demais curiosidades, etc. }\end{array}$ \\
\hline & $\begin{array}{l}\text { Site do grupo USS Venture (www.ussventure.eng.br): no site existem } \\
\text { informações sobre todo o Universo Star Trek, bem como as informações de } \\
\text { todos os membros que entraram como tripulantes. }\end{array}$ \\
\hline & $\begin{array}{l}\text { Revista Tribuna Quark: editada pelo proprietário da ilha, contém artigos } \\
\text { diversos sobre a série e cobertura de eventos na vida real. }\end{array}$ \\
\hline Plataforma Second Life & $\begin{array}{l}\text { São consumidas missões com presença de membros do grupo, } \\
\text { treinamentos paramilitares dentro da plataforma (treinamento de pilotagem } \\
\text { de naves, defesa com armas, de coleta de 'dilitium' - material usado na série } \\
\text { para gerar energia e é uma atividade necessária para que virtualmente a } \\
\text { base principal não pare de funcionar }{ }^{3} \text { ); debates informais com trocas de } \\
\text { informações sobre filmes, produtos e ideologias associadas ou não com a } \\
\text { série; criam-se uniformes para os membros; consumo de filmes dentro do } \\
\text { ambiente. }\end{array}$ \\
\hline
\end{tabular}

Fonte: Dados de pesquisa.

Quadro 1. Consumo na Plataforma Second Life

A estrutura de comportamento do microgrupo composta por líder e liderados assemelhando à estrutura militar é um comportamento de indivíduos ligados à estrutura de subgrupos trekkie. Nesta estrutura são identificados: integração dos pares (dentro e fora do SL); recepção de indivíduos externos de forma amigável; protecionismo intragrupo claramente definido; hostilidade leve intergrupos de forma localizada, com vistas à supervalorização do grupo, resultado semelhantemente encontrado por Kozinets (2001).

0 grupo de fãs permite o acesso à ilha de Trivas a qualquer pessoa que esteja dentro do Second Life, mesmo que a ilha seja paga mensalmente ${ }^{4}$. Para manter o sistema ativo, sem que seja apagado, o ambiente virtual deve ser pago mensalmente, o que sempre é feito por dois membros da USS Venture que se dispuseram a arcar com tais custos. 0 valor aproximado do aluguel mensal é de $\mathrm{R} \$ 1.500,00$ e os membros que mantém a ilha ativa, justificam este ato porque almejam que 0 acesso e a ideologia do UST seja mantida viva, num lugar onde os fãs podem vivenciar as missões, treinamentos ou o simplesmente ter contato com outros fãs, conforme explicado, em entrevista informal, por um dos proprietários e mantenedor principal da ilha.

A ilha foi criada por fãs há 10 anos e hoje é mantida para fins de entretenimento associado ao UST. Em termo de teorias de comportamento de consumo, a ilha de Trivas é um Crowdsourcing mantido financeiramente por duas pessoas; e por integrantes com conhecimentos intelectuais específicos, tais como: programadores para atualização do sistema virtual; construtores de cenários e naves, designers de uniformes e skins, jornalismo e comunicação dentro e fora do SL, materiais didáticos para os treinamentos (provas teóricas), aplicação de provas práticas e treinamentos, membros que se intercalam na 
criação e liderança de missões, na criação de atividades culturais e saídas de campo. Um dos "mecenas" de Trivas, externalizou que utiliza o acesso à ilha como fins de indicação médica para apaziguar stress da ocupação na vida real, este, faz questão de manter as funcionalidades dos códigos de programação da ilha atualizados e os ambientes virtuais dinâmicos para comportar novas missões com novos cenários e idumentárias dos personagens.

Os dados foram coletados a partir de entrevistas informais com seis membros ativos (dois comandantes principais e demais tripulantes com o mínimo de dois anos como membro), com intenção de conhecer a história da formação do grupo e dos membros, bem como, conhecer o sistema Second Life. Durante a pesquisa, aproximadamente treze membros estavam ativos e participando das atividades e os dados foram coletados entre os meses de julho de 2016 e julho de 2017.

b) Eventos: 20a e 21 ${ }^{\mathrm{a}}$ Trekcon

Foi realizada observação participante em dois eventos Trekcon, organizados pelo fã clube Federação dos Planetas Unidos, em 2016 (Figura 3) apenas como participante e no evento em 2017 como parte da equipe organizadora do evento. Os eventos são oportunidades para demonstrar a atividade do grupo, os itens colecionados pelos membros, fazer cosplay (Figura 4) e para oportunizar conhecimento dos membros sobre o UST para a sociedade em geral. Existem durante o evento diversas formas de consumo, que vão desde a oportunidade de compartilhar conhecimentos sobre o UST e consumir esta oportunidade, passando pela venda e aquisição de itens relacionados ao universo e ao cosmouniverso Nerd/Geek, até assistir a alguns episódios e filmes.

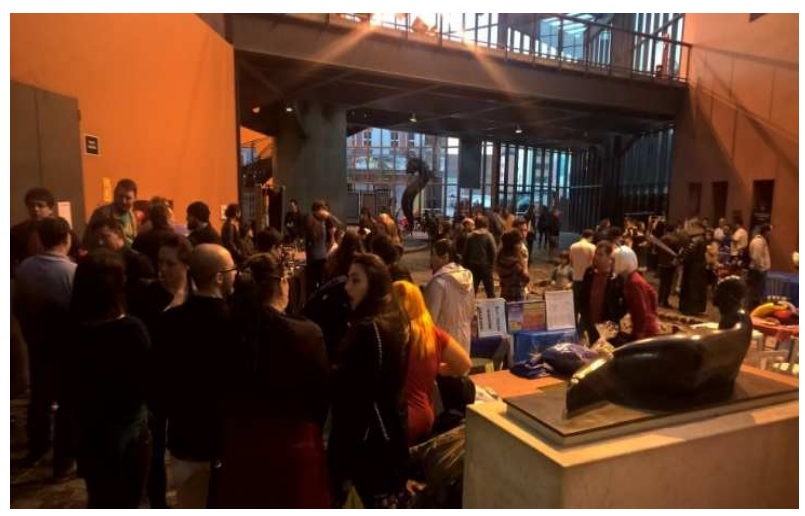

Fonte: Dados de pesquisa.

Figura 3. 20ํㅡㄹ Trekcon Curitiba

Em alguns momentos, nos dois eventos, eram vistas imitações de poses, e ouvidas reproduções de diálogos e de expressões verbais relacionadas com a série.

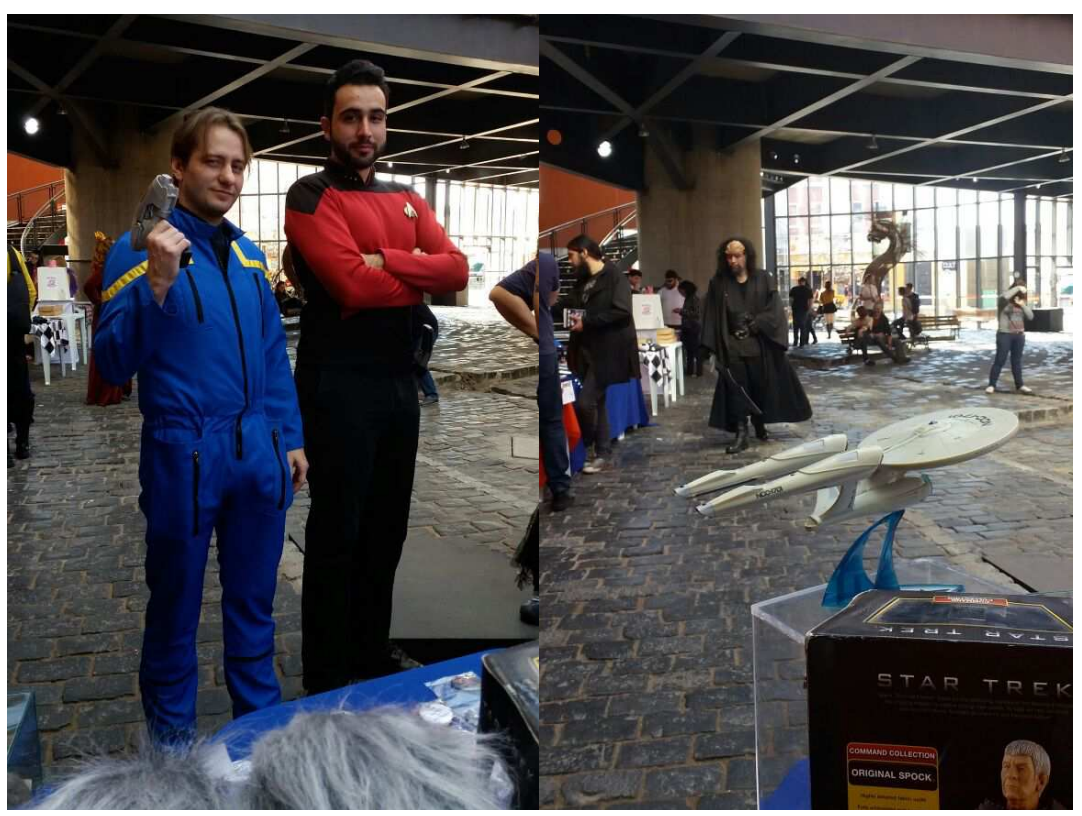

Fonte: Dados de pesquisa.

Figura 4 e 5. 21 $\underline{\text { a }}$ Trekcon: Cosplay do grupo Star Trekkers* e Cosplay do grupo FPU** *Cosplay de tripulantes da série ENT e da série TNG; ** Cosplay de da espécie Klingon 
Na edição de 2017, 21 $1^{\text {a }}$ Trekcon, o autor que participou como membro da FPU, pôde acompanhar o processo de organização do evento, contribuindo com a confecção de chaveiros para ser vendido durante o evento, para angariar dinheiro para custear as despesas do mesmo. Alguns membros do grupo se reuniu para confeccionar itens para a venda em eventos que envolvem o universo Nerd, pois, por não ser uma organização com fins lucrativos, eventos para angariar dinheiro ocorrem de acordo com a necessidade para o fim específico da Trekcon. Os itens criados pelos membros foram memorabílias, botons, imãs de geladeira, adesivos para unhas, próteses dentárias e chaveiros (Figura 6).

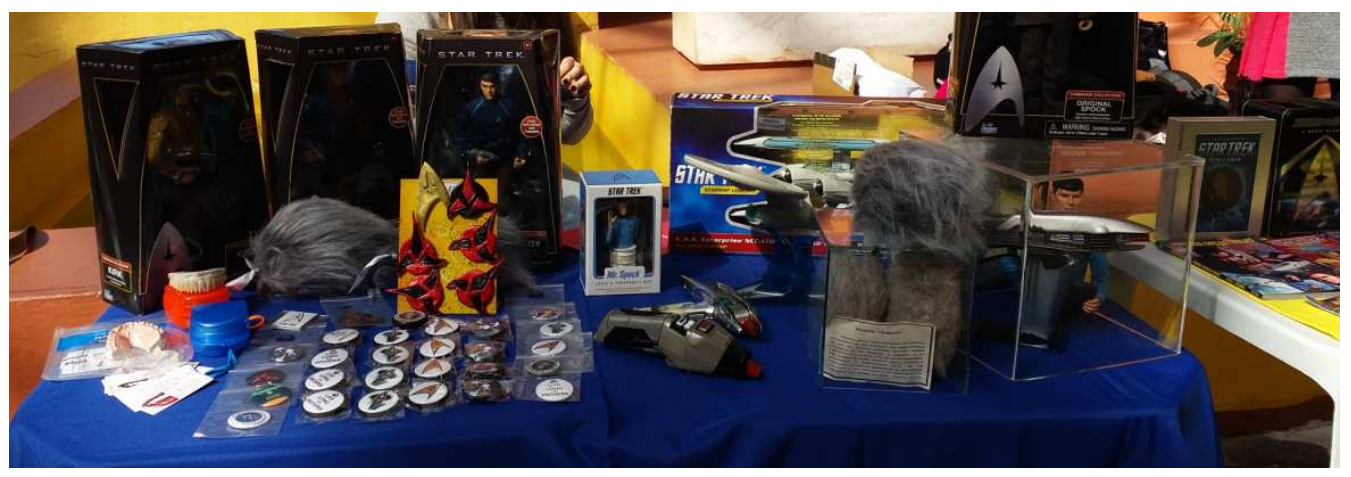

Fonte: Dados de pesquisa.

Figura 6. $21^{\mathrm{a}}$ Trekcon: Itens confeccionados pelos membros para venda

Em geral, os eventos servem para demonstrar para sociedade a presença do grupo, para compartilhar conhecimentos e fazer com que a sociedade tenha acesso a esta cultura. Além disso, os eventos servem como interlocutores da cultura nerd por permitir que outros fandoms exponham suas coleções e produtos, neste caso, o fã clube serve como apoiador a outros grupos e expressão representante da cultura nerd, tanto locais, nacionais ou mesmo internacionais.

\section{Expressão material do consumo}

Para Dorneles (2002, p. 95) “(...) o consumo produz determinadas inscrições nos corpos que mostram as diferenças sociais e culturais dos sujeitos", pois não se consome apenas o objeto, mas tudo o que está presente e que se deseja representar, sendo possível consumir as imagens e materializá-las em si mesmo, e tê-las inscritas em si significa fazer pertencer-se a um espaço perpassado pelo poder, que distingue, mas também homogeniza (Dorneles, 2002).

Os discursos dos fãs demonstram como os objetos, as coisas ou artefatos participam das práticas sociais ao serem usados, aplicados e mantidos e, entendidos na sua materialidade (Latour, 1996, Abolafia, 1998). Para Shove e
Araujo (2010) os objetos e sua materialidade tem implicações com fases de transformações individuais nas quais os significados dos artefatos dependeriam de contextos individuais e particulares onde os indivíduos estão inseridos. Assim, na primeira fase, chamada apropriação, o objeto tecnológico é transferido e transformado em artefato que contém significância e significado para o usuário; em seguida, na fase de objetificação, o artefato é mostrado ou alinhado com outros artefatos, que traduzem significados estéticos e cognitivos para os usuários; no terceiro momento ocorre a incorporação, que é a inserção do artefato no uso diário e na rotina do usuário.

Nesta pesquisa a expressão material é conferida pela disponibilidade dos produtos para consumo, sejam eles materiais ou imateriais assim, procedeu-se com o levantamento dos sites que disponibilizaram para compra produtos relacionados ao UST.

Foram relacionados sete sites (Quadro 2) que trabalham com produtos ligados ao tema Star Trek vendidos no Brasil: brinquedos, actions figure, roupas infantis e adultas, para ambos os gêneros, DVDs, Blue-rays, livros, petshop, entre outros conforme demonstrado na tabela abaixo. Através desse levantamento 
foi possível perceber que há diversas categorias de produtos à venda ligados ao tema, mas a variedade de produtos relacionados é pequena e relacionada à demanda sazonal em períodos de lançamento dos filmes.

\begin{tabular}{|l|l|}
\hline \multicolumn{1}{|c|}{ Lojas } & \multicolumn{1}{|c|}{ Produtos } \\
\hline Loja Mundo Geek & $\begin{array}{l}\text { Actions Figures, vestuário (camisetas femininas e masculinas, moleton } \\
\text { feminino, body infantil), cofres. }\end{array}$ \\
\hline Americanas & $\begin{array}{l}\text { Brinquedos, livros, utilidades domésticas, games, moda, informática } \\
\text { acessórios, livros importados, dvds e blu-ray, relógios, vestuário esportivo, } \\
\text { blu-ray. }\end{array}$ \\
\hline Merchandising Plaza & $\begin{array}{l}\text { Canecas, acessórios, utilitários domésticos, bolsas, carteiras, action figures, } \\
\text { brinquedos, broches, etiqueta de bagagem, brinquedos, maquetes. }\end{array}$ \\
\hline Saraiva & Brinquedos, filmes, jogos, livros. \\
\hline Quarto Geek & Utilidades domésticas, decoração. \\
\hline Submarino & $\begin{array}{l}\text { Livros (nacionais e importados), jogos, brinquedos, acessórios de } \\
\text { informática, vestuário (esportivo), decoração, blu-ray. }\end{array}$ \\
\hline Fnac & Livros, miniaturas, vestuário (camisetas). \\
\hline
\end{tabular}

Fonte: Dados de pesquisa.

Quadro 2. Sites e produtos para compra

Através desse levantamento foi possível perceber que o Universo Star Trek movimenta diversas categorias de produto. Entende-se que o papel da materialidade no consumo é essencial para compreender os mercados e consumidores, pois os produtos em sua materialidade não só tem papel ativo na constituição, sustentação e transformação das práticas de mercado (Shove \& Araujo, 2010), mas também na prática de significação e ressignificação da identidade individual e coletiva dos Trekies. Somente pelo acesso aos materiais e produtos disponíveis é que um consumidor tem a possibilidade de interagir com o grupo que almeja, no presente caso, o dos fãs de Star Trek, é de alcançar satisfação pessoal e identidade individual no coletivo.

\section{Identificação do fã junto aos pares}

Os grupos em sua maioria são criados e formalizados atualmente de maneira online e a partir deste agrupamento de fãs, são efetivadas as ações práticas ou físicas. Os fãs interagem nos grupos em redes sociais e por trocas de mensagens instantâneas e páginas relacionadas ao UST. Estas são maneiras pelas quais se compartilham e formalizam as discussões/ informações sobre este universo, sobre as atividades, dúvidas e representações de ideias pessoais sobre a série. É nesses grupos que o fã formaliza seu posicionamento quanto à série e as ideias que ela apresenta, buscando novas referências de informações e ressignificando por meio disso, o que já havia apreendido em relação à série ou filme.

\section{a) Redes sociais}

Dentre os vários grupos existentes, o Fã clube Star Trekkers é o grupo brasileiro com maior número de membros (aproximadamente 4500 membros). 0 grupo trata de assuntos ligados ao universo de Star Trek de modo geral, oportuniza informações sobre textos criados, notícias relacionadas aos atores, personagens, lançamentos, memes, fotografias, oferece informações gerais sobre as atividades do fã clube, etc.

b) Whatsapp

A intenção em acompanhar os grupos pelo whatsapp foi de observar que tipo de informações os fãs trocam. No aplicativo de troca de mensagens, foram investigados três grupos, os fã clubes brasileiros: Star Trekkers, Federação dos Planetas Unidos e USS Venture.

- Star Trekkers (2016-2017): As mensagens trocadas, de modo geral, referem-se a produtos como memorabilias; indagações e explicações sobre as séries e filmes; manifestações 
em defesa da série; compartilhamento de imagens e vídeos; debates sobre o entendimento da filosofia representada na série; divulgação de campanhas de doação de sangue, eventos e encontros; sugestão de episódios e filmes; divulgação de produtos em lançamento (naves, coleções, cosméticos, etc.). A quantidade de fãs que fazem parte das discussõe varia entre 90 e 100 integrantes, com mensagens diárias.

- Grupo: USS Venture - Second life (2016): As mensagens trocadas são sobre as atividades a serem desenvolvidas na ilha como reuniões, eventos, melhorias, datas das missões, novas programações, etc. Não foi observado sugestão de produtos para compra diretamente no grupo, porém no site há divulgação de produtos lançados, filmes, etc. A quantidade de integrantes varia no decorrer do ano, nas épocas de final de ano e até meados de abril existe maior frequência e participação tanto na plataforma quanto no grupo do aplicativo e em outros momentos a frequência diminui.

- Grupo: Federação dos Planetas Unidos (2016-2017): São trocadas mensagens sobre participação do fã clube em eventos, informações sobre reuniões, confraternização, compartilhamento de imagens e vídeos relacionados ou não sobre o UST Não foi observada sugestão de produtos para compra. A quantidade de integrantes tem variação entre 10 e 15 membros, e as mensagens tinham frequência esporádica semanal.

\section{ANÁLISE}

A partir dos dados levantados, os resultados apontam para um Canon do consumo do Universo Star Trek brasileiro. Pode-se identificar que o acesso aos filmes e séries ocorre como modelo diretivo para o fã, esta ação é a ativação do consumo do UST. No Brasil, os fãs interagem diariamente por meio das redes sociais, programas de trocas de mensagens e pelo uso da plataforma Second Life, sendo o consumo como participação ou play aquele visualizado como a representação mais clara da metáfora de consumo de Holt (1995). Esta interação possibilita o direcionamento e auxilio à compra de produtos e serviços do UST, porém, este consumo ocorre pela iniciativa individual e não pela sugestão coletiva de compra dentro destes grupos. Esta expressão material é limitada pela disponibilidade de produtos para compra no país, que em comparação com sites de vendas de outros países tem uma oferta bem reduzida na quantidade de produtos, e apresenta preço de venda superior ao estabelecido em outros países.

Nos fãs clubes, os fãs podem expressar sua defesa em referência ao filme ou série de preferência o que muitas vezes leva a discussões profundadas sobre: qualidade da representação da ficção científica, qualidades interpessoais e intelectuais dos personagens, encantamento com ideologia e fisionomia dos personagens de outras raças, etc.. E a partir desta defesa e absorção de informações de pares, pode ocorrer a ressignificação do UST, pois, o diáligo, a teatralização, as notícias recentes, e as novas formas de entender este universo permitem ressignificar o que o fã já havia compreendido sobre a ideologia do Universo Star Trek.

Assim, com a intenção de esclarecer como ocorre o consumo no Brasil é proposta a criação de um modelo ideológico ou um Canon do consumo do Universo Star Trek no Brasil, conforme demonstrado na Figura 7.

\section{CONSIDERAÇÕES FINAIS}

Esta pesquisa buscou demonstrar as reflexões sobre a cultura de consumo no Brasil, especificamente no tocante ao consumo do Universo Star Trek. O objetivo principal de descrever o consumo deste universo diante de diversas fontes de dados foi cumprido, juntamente com a identificação dos pressupostos de ativadores do consumo, do consumo como participação, da expressão material do consumo e da identificação do fã junto a seus pares. 0 fã, o trekkie, não só acompanha e consome os filmes e séries, mas também faz questão de buscar outras formas de consumo tais como participar de fã clube, participar de eventos e encontros, acessar a plataforma Second Life, dentre outros, que 
permitam a troca de informações e vivenciar os valores do UST que extrapolam ao simples ato de simplesmente assistir em vídeo.

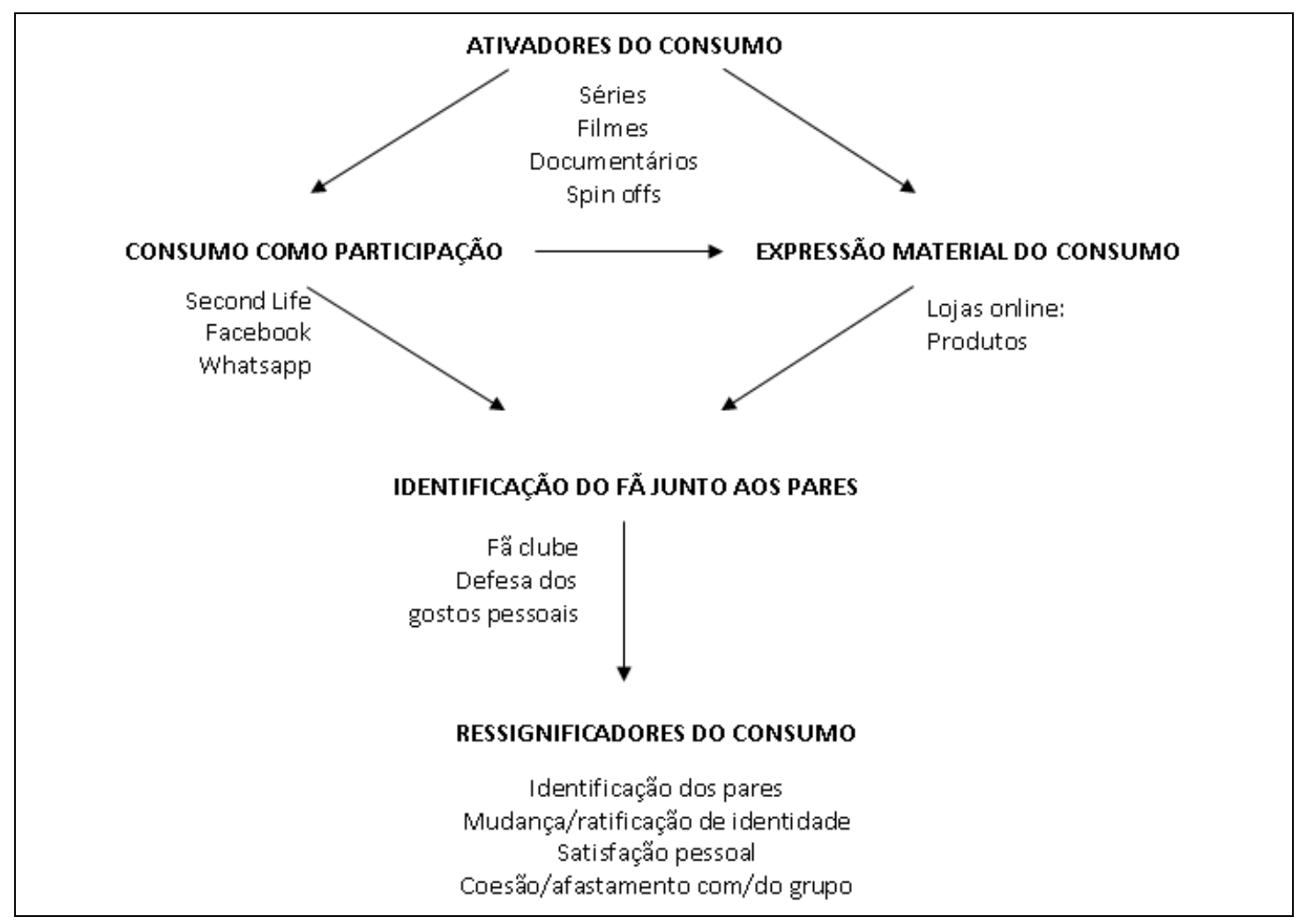

Fonte: Elaborado pelos autores.

Figura 7. Canon do consumo do Universo Star Trek no Brasil

A partir da identificação e análise das diversas formas de consumo, foi proposta a criação de um Canon do consumo do Universo Star Trek pelo consumidor brasileiro. A proposta do Canon segue o raciocínio de que o acesso dos fãs brasileiros aos textos e vídeos é o ativador do consumo, tanto ele pode ser visto como consumo autotélico e como prospector de consumo dos artefatos. Os fãs comunicam o Universo entre os pares com vistas a compartilharem formas de compreender a série, personagens e filmes, porém, a indicação de consumo de artefatos materiais é esporádica, partindo dos fãs individualmente e não coletivamente, apesar de compartilharem do universo coletivamente nas redes sociais.

A partir da pesquisa foram identificados e analisados os meios e grupos de comunicação dos Trekkies, com vistas a identificar os produtos disponíveis para consumo de fácil acesso no Brasil, a expressão material realizada por meio deste consumo e os possíveis resultados deste consumo. Os grupos apresentam características específicas, onde a formalização ou organização decorre com o intuito de ser identificado socialmente como fã, conforme encontrado na pesquisa de Kozinets (1997).

Quanto às limitações de pesquisa cabe salientar, que estes dados são resultado de pesquisa na qual a maior parte dos dados foi obtida por observação participante, presencialmente e em plataformas virtuais e como, ocorrendo a possibilidade de não representar a verdade expressada no meio virtual, que pode representar uma lacuna em relação a verdade falada, representada, pesquisada e efetivada.

Como sugestão para futuras pesquisas, devido a diversidade dos perfis dos personagens do enredo do UST nas diversas séries e filmes, poderiam ser exploradas as 
expressões de consumo de cada perfil de personagem para identificar se existe algum padrão atrelado a algum ou alguns desses personagens, cultura ou raça. Seria interessante explorar mais profundamente o que chamamos de ideias de consumo como a visão do não desperdício, a aceitação ou rejeição dos alimentos e produtos sintetizados, a troca cultural e de objetos com outras espécies, ideias de economia de recursos, conhecimento intelectual como ideal, dentre outras. Por fim, sugere-se estudar os atuais direcionamentos de fãs brasileiros que por meio de crowdfunding conseguiram mais de trinta mil reais para trazer ator ou atriz que participou da série Deep Space Nine para participar de evento no Brasil.

\section{REFERÊNCIAS}

Abolafia, M. Y. (1998). Markets as cultures: An ethnographic approach. In: CALLON, Michel. (Ed.). The laws of the markets (pp. 69-85). Oxford: Blackwell Publishers.

Arnould, E. J., \& Thompson, C. J. (2005). Consumer Culture Theory (CCT): Twenty years of research. Journal of Consumer Research, 31(4), 868-882.

Bardin, L. (1979). Análise de conteúdo. Lisboa: Edições 70.

(2006). Análise de conteúdo. Lisboa: Edições70.

Belk, R. W. (1988). Possessions and the extended self. Journal of Consumer Research, 15(2), 139-168.

Campbell, C. (2005). The craft consumer: Culture, craft and consumption in a postmodern society. Journal of Consumer Culture, 5(1), 23-42.

Dorneles, L. V. (2002). Meninas no papel. Tese Programa de Pós-Graduação em Educação. Faculdade de Educação. Universidade Federal do Rio Grande do Sul, Porto Alegre.

Dubois, A., \& Gadde, L-E. (2002). Systematic combining: an abductive approach to case research. Journal of Business Research, 55, 553-560.

Duffett, M. (2013). Understanding fandom: An introduction to the study of media fan culture.1st Ed. New York: Bloomsbury Academic.

Entertainment Weekly. (1994). To Boldly Go Where No One Has Gone Before.... Entertainment Weekly "Special Obsessive-Compulsive Collector's Star Trek Edition") (Fall), 8-9.
Featherstone, M. (1991). Consumer culture and postmodernism. London: Sage.

Fiske, J. (1987). Television culture. London: Methuen. (1989). Understunding popular culture. Boston: Unwin Hyman.

Frazetti, D. G. (2016). The culture of Trek fandom: wouldn't you like to be a trekkie too? (publicação individual). Recuperado em 16 fevereiro, 2018, de https://www.academia.edu/461218/Results_ Star_Trek_Fandom_Survey.

Goldsmith, R. E., \& Clark, R. A. (2012). Materialism, status consumption, and consumer independence. The Journal of Social Psychology, 152(1), 43-60.

Grossberg, L. (1992). Is there a fan in the house?: The affective sensibility of fandom. In: Lewis, L. A. (Ed.) The Adoring Audience: Fan Culture and Popular Media. London: Routledge, 50-65.

Hollenbeck, C. R., \& Patrick, V. M. (2016). Mastering survivorship: How brands facilitate the transformation to heroic survivor. Journal of Business Research, 69 (1), 73-82.

Holt, D. B. (1995). How consumers consume: A typology of consumption practices. Journal of Consumer Research, 22(1-June), 1-16.

Kozinets, R. V. (1997). To boldly Go: A hypermodern ethnographyof Star Trek @ Fins' Culture and Communities of Consumption. (Tese) - The School of Business in Queen's University, Kingston, Ontario, Canada, July. (2001). Utopian Enterprise: Articulating the Meanings of Star Trek's Culture of Consumption. Journal of Consumer Research, 28(1 June), 67-88.

(2002). Special Session Summary Utopian Consumption. In: Broniarczyk, S.M., \& Nakamoto, K. (eds). Advances in Consumer Research, 29, 62-64. Valdosta, GA: Association for Consumer Research.

Latour, B. (1996). Que peuvent apporter l'histoire et Ia sociologie des sciences aux sciences de gestion?. Actes des 13emes journees nationales des IAE, Toulouse, ESUG, tire a part, 3-15.

Lee, S. H., \& Luster, S. (2015). The social network implications of prestigious goods among young adults: evaluating the self vs others. Journal of Consumer Marketing, 32(3), 199 208.

Levy, S. (2015). Roots and development of consumer culture theory. Keynote address delivered at the 10th Consumer Culture Theory Conference, Fayeteville, AK: University of Arkansas, June 19th.

Lewis, L. A. (Ed.) (1992). The adoring audience: Fan culture and popular media. London: Routledge, 50-65. 
Mccracken, G. (1986). Culture and Consumption: a theoretical account of the structure and movement of the cultural meaning of consumergoods. Journal of Consumer Research, 13(June), 71-84.

Minayo, M. C. de S. (2000). O desafio do conhecimento: pesquisa qualitativa em saúde. 7 ed. São Paulo: Hucitec.

Paramount Brasil. (2016). O fenômeno jornada nas estrelas. Recuperado em 16 fevereiro, 2018, de

http://www.paramountbrasil.com.br/star_tre k_40_anos/criador.htm.

Schouten, J. W., \& Mcalexander, J. H. (1995). Subcultures of Consumption: an ethnography of the new bikers. Journal of Consumer Research, 22(June), 43-61.

Shove, E., \& Araujo, L. (2010). Consumption, materiality, and markets. In: Araujo, L., Finch, J., \& Klellberg, H. (Eds.) Reconnecting marketing to markets. Oxford: Oxford University Press, 13-28.

Simmel, G. (1950). The sociology of Georg Simmel. ed. Kurt Wolff, New York: Free Press.

Sirsi, A. K., Ward, J. C., \& Reingen, P. H. (1996). Microcultural analysis of variation in sharing of causal reasoning about behavior. Journal of Consumer Research, 22(4), March, 345-372.

Solomon, M. R. (1983). The role of products as social stimuli: a symoblic interactionism perspective. Journal of Consumer Research, 10, 319-329.

Taheri, B., Gori, K., O'gorman, K. D., Hogg, G., \& Farrington, T. (2015). Experiential liminoid consumption: The case of nightclubbing. Journal of Marketing Management, 32(1-2), 19-43.

Trek Brasilis. (2016). 0 nascimento de um ícone cultural. Recuperado em 16 fevereiro, 2018, de

http://www.trekbrasilis.org/classico/breve.h tm.

Tulloch, J., \& Jenkins, H. (1995). Science fiction audiences: Watching Doctor Who and Star Trek. London and New York: Routledge.

USS Venture. (2018). USS Venture no second life - SL. Recuperado em 16 fevereiro, 2018, de http://www.ussventure.eng.br/index2.htm

Vieira, E. (2017). Entrevista com Adriana Amaral sobre estudos de fãs no Brasil. Recuperado em 16 fevereiro, 2018, de https://www.ibpad.com.br/blog/entrevistacom-adriana-amaral-sobre-estudos-de-fas-nobrasil/.

Vieira, V. A., \& Appio, J. (2010). O Impacto da Conexidade no Comportamento do Consumidor em Relação aos Programas de Televisão. RAC - Revista de Administração Contemporânea, Curitiba, 14 (4), 703-721.

\footnotetext{
${ }^{1}$ IMDb: é o Internet Movie Database, é a Base de Dados de Filmes que contempla informações sobre cinema, filmes, música, series, comerciais de tv e jogos (http://www.imdb.com/)

2 PBEM que dizer "Play by e-mail", derivado do RPG (Roling play game), mas feito por e-mail.

3 Criado pelos idealizadores da ilha para coexistir como atividade do ambiente para manter o treinamento dos avatares. Garantindo maior fidedignidade com a série.

4 Aluga-se uma ilha para manter as construções virtuais, neste caso, são naves e planetas que compreendem o UST. Cabe salientar que algumas ilhas exigem pagamento para obter acesso às instalações no Second Life.
}

\title{
The Canon of Consumption of the Star Trek Universe in Brazil
}

\begin{abstract}
This research concerns to aims to describe how the consumption of the Star Trek Universe (UST) by fans in Brazil occurs. Following the assumptions regarding the Consumer Culture Theory, the research with qualitative nature and descriptive purposes, and from the analysis of content sought to identify and describe the consumption by immersion in the fan environment of Star Trek in Brazil. The data were collected from: observation and interviews with fan groups in social communities such as Second Life, facebook and whatsapp; membership in fan clubs and face-to-face events; by the analysis of series, films and documentaries; as well as identification of products for consumption for searches on google. The results suggest the creation of a Canon of the Star Trek Consumer Culture and this one explains the consumption of the UST in the country.
\end{abstract}

Keywords: Star Trek, Fans, Consumer culture, Consumption metaphors, Material expression. 